\title{
Brucellosis Concurrent with Johne's disease Infection in a Buffalo Bull
}

\author{
Eric Lim Teik Chung ${ }^{1,2}$, Faez Firdaus Abdullah Jesse ${ }^{2,3 *}$, Asinamai Athliamai Bitrus ${ }^{5}$, \\ Innocent Damudu Peter ${ }^{3,4}$, Nur Azhar Amira ${ }^{3}$, Bura Thlama Paul ${ }^{3}$, Idris Umar Hambali ${ }^{4}$, \\ Mohd Azmi Mohd Lila ${ }^{3}$, Mohd JEFri Norsidin ${ }^{3}$
}

${ }^{1}$ Department of Animal Science, Faculty of Agriculture, Universiti Putra Malaysia, 43400 Serdang, Selangor, Malaysia, ${ }^{2}$ Institute of Tropical Agriculture and Food Security, Universiti Putra Malaysia, 43400 Serdang, Selangor, Malaysia, ${ }^{3}$ Department of Veterinary Clinical Studies, Faculty of Veterinary Medicine, Universiti Putra Malaysia, 43400 Serdang, Selangor, Malaysia, ${ }^{4}$ Faculty of Veterinary Medicine, University of Maiduguri. P.M.B 1069 Maiduguri, Borno Nigeria, ${ }^{5}$ Research Unit, Microbial Food Safety and Antimicrobial Resistance, Department of Veterinary Public Health, Faculty of Veterinary Science, Chulalongkorn University, 10330 Pathumwan Bangkok, Thailand.

\begin{abstract}
This case report describes a veterinary clinical case of brucellosis concurrent with Johne's disease in a buffalo bull that highlight the clinical and diagnostic management of the case. A 3-year-old Murrah buffalo bull weighing 250 $\mathrm{kg}$ with a body condition score of 2 out of 5 was presented with the primary complaint of decreasing body weight for the past one month. The most obvious signs observed during physical examinations were emaciation with prominent bony structures and enlargement of the scrotum. Upon palpation, the testicles were firm in consistency and warm. The differential diagnoses at that point of time were brucellosis, Johne's disease, and Fascioliasis. The biochemical finding revealed hyperglobulinaemia $(55.5 \mathrm{~g} / \mathrm{L})$ and the Rose Bengal Plate Test showed result of agglutination with the serum sample. Bacteriology finding demonstrated a positive result for acid-fast bacillus using the Ziehl-Neelsen's stain method. Based on the history, physical examinations, and diagnosis work-ups, the buffalo bull was diagnosed infected with brucellosis concurrent with Johne's disease infection. The prognosis of the case was grave and the animal was not treated due to the test-and-slaughter policy in Malaysia to control brucellosis. The farmer was advised to screen all animals on his farm as prevention and control for both diseases.
\end{abstract}

Keywords | Buffalo, Bull, Brucellosis, Johne’s disease, Clinical management.

Received | March 31, 2018; Accepted | July 05 2019; Published | August 26, 2019

${ }^{*}$ Correspondence | Faez Firdaus Abdullah Jesse, Institute of Tropical Agriculture and Food Security, Universiti Putra Malaysia, 43400 Serdang, Selangor, Malaysia; Email: jesse@upm.edu.my

Citation | Chung ELT, Jesse FFA, Bitrus AA, Peter ID, Amira NA, Paul BT, Hambali IU, Lila MAM, Norsidin MJ (2019). Brucellosis concurrent with johne's disease infection in a buffalo bull. Adv. Anim. Vet. Sci. 7(9): 788-790.

DOI | http://dx.doi.org/10.17582/journal.aavs/2019/7.9.788.790

ISSN (Online) | 2307-8316; ISSN (Print) | 2309-3331

Copyright $\odot 2019$ Chung et al. This is an open access article distributed under the Creative Commons Attribution License, which permits unrestricted use, distribution, and reproduction in any medium, provided the original work is properly cited.

$\mathrm{T}$ he domestic water buffalo is further classified into swamp and river type buffalo that are mostly used for beef and milk production respectively. For example, Murrah buffaloes are higher milk producers compared to the dairy cow in the tropical climate (Abd El-Salam and E1-Shibiny, 2011). Agreeing to Jesse et al. (2018), inefficient disease prevention and control is one of the main factor contributing to the gap in the dairy and beef industry including buffalo. In cattle and buffaloes, B. abortus and B. melitensis are the two main species of brucellosis causing reproductive problems in both female and male animals (Asinamai et al., 2018). Affected animals may show sign of abortion in the last trimester of gestation in females and testicular abscesses or orchitis in males (Sousa et al., 2017). Johne's disease or also known as paratuberculosis is a wasting, chronic granulomatous enteritis affecting domestic ruminants including cattle, buffalo, goats, sheep, and camels. The causative agent is Mycobacterium paratuberculosis, a gram-positive and slow-growing acid-fast bacillus (Manning, 2011). Therefore, the purpose of the present veteri- 
nary case report was to describe the clinical and diagnostic management of a Murrah buffalo bull infected with brucellosis and Johne's disease.

A 3-year-old Murrah buffalo bull weighing $250 \mathrm{~kg}$ with a body condition score of 2 out of 5 was presented with the primary complaint of decreasing body weight for the past one month. The bull was managed semi-intensively where the vaccination and deworming status were up-todate. Physical examination revealed that the buffalo bull appeared to be bright and alert with good appetite (Figure 1). Clinical evaluation revealed that the vital parameters were within the normal range and the mucous membrane was pink with a capillary refill time of less than two seconds. The most obvious signs were emaciation with prominent bony structures and enlargement of the scrotum. The testicles were firm in consistency and warm upon palpation. Rectal palpation revealed no corrugation at the large intestine (Figure 2). The differential diagnoses at that point of time were brucellosis, Johne's disease, and Fascioliasis.

For Diagnosis Work-Ups, blood samples were collected via jugular venipuncture into plain blood tubes for serum biochemistry analysis and Rose Bengal Plate Test (RBPT). The biochemical finding revealed hyperglobulinaemia $(55.5 \mathrm{~g} / \mathrm{L})$ which may be due to chronic inflammatory diseases. Consequently, the Total Protein concentration $(88.5 \mathrm{~g} / \mathrm{L})$ was higher because of the hyperglobulinaemia. Results for the other blood parameters were insignificant (Table 1). The RBPT showed agglutination with the serum sample indicating a positive result for brucellosis. The disease was confirmed with the complement fixation test (CFT). In addition, faecal samples were also sampled per rectum for parasitology and bacteriology examinations. There was no significant result from the faecal sedimentation test to rule out liver fluke infestation. However, bacteriology finding demonstrated a positive result for acid-fast bacillus using the Ziehl-Neelsen's stain method. Based on the physical examination, serum biochemistry analysis, RBPT, parasitology, and bacteriology test, the buffalo bull was diagnosed to have brucellosis concurrent with Johne's disease infection. No treatment was given due to the grave prognosis and the animal was culled according to the testand-slaughter policy practiced in Malaysia to control brucellosis. The farmer was advised to report to the authority for the screening of all animals on his farm as prevention and control for both diseases. The case was reported to the Department of Veterinary Services, Malaysia as the disease diagnosed is a reportable disease to the authority for further screening and prevention strategy to be implemented in the affected farm.

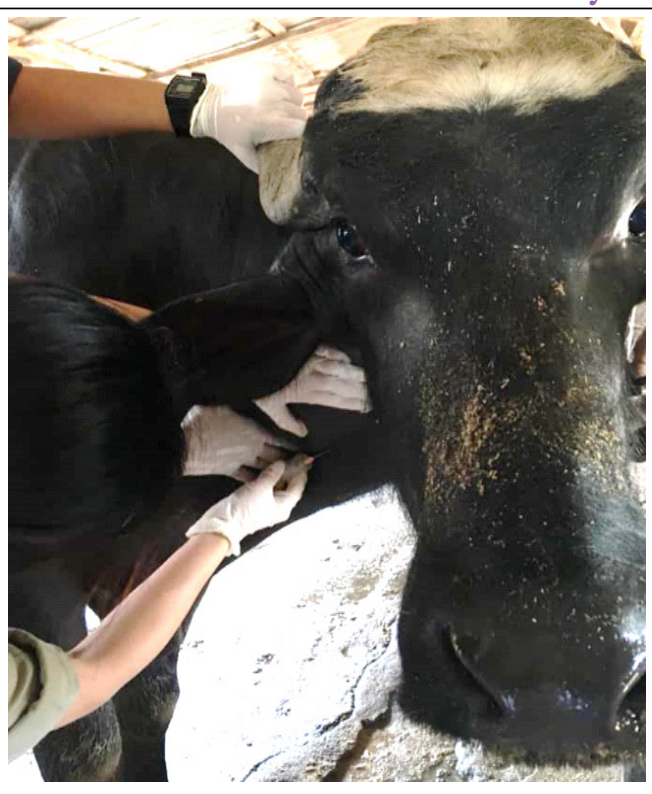

Figure 1: The buffalo bull appeared to be bright and alert. Blood sample was collected via jugular venipuncture.

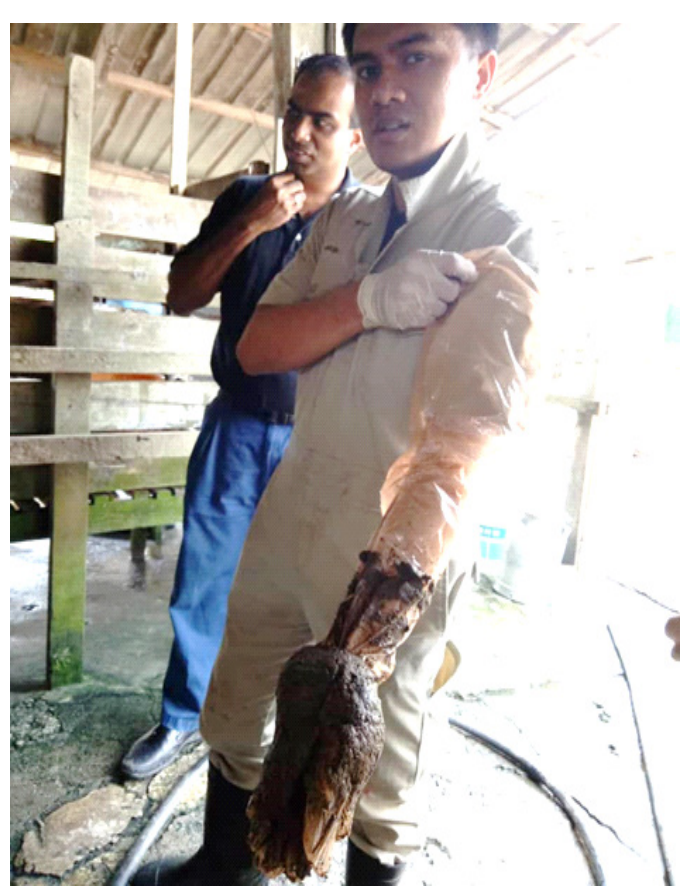

Figure 2: Rectal palpation was conducted to detect corrugation of the large intestine. Faecal sample was collected per rectum.

Table 1: Serum biochemistry results of the emaciated buffalo bull.

\begin{tabular}{lll} 
Parameters & Result & Reference range \\
\hline Bilirubin, Total $(\mu \mathrm{mol} / \mathrm{L})$ & 6.4 & $1.7-27.2$ \\
Bilirubin, Conjugated $(\mu \mathrm{mol} / \mathrm{L})$ & 0.3 & $<10.2$ \\
Total Protein $(\mathrm{g} / \mathrm{L})$ & 88.5 & $55-75$ \\
Albumin $(\mathrm{g} / \mathrm{L})$ & 33.0 & $24-40$ \\
Globulin $(\mathrm{g} / \mathrm{L})$ & 55.5 & $27-45$ \\
A:G (Unit) & 0.6 & $0.8-1.2$ \\
\hline
\end{tabular}


According to Sousa et al. (2017), brucellosis has been officially eradicated in some countries, yet the disease is still endemic in Malaysia. For that reason, the Malaysian authorities have introduced the test-and-slaughter policy in an attempt to control and eradicate brucellosis which was reported in the current case study. Despite the implementation of eradication measures, the epidemiological situation of brucellosis in ruminants is still problematic due to the inefficient disease diagnosis, prevention, and control (Jesse et al., 2018). The clinical sign of enlarged scrotum demonstrated in the case report was in accord with Khan and Line (2005). Sousa et al. (2017), stated that the Brucella organism has a strong tropism for the reproductive systems. The buffalo bull may get infected via the oral, nasopharyngeal, conjunctival mucosa or broken skin before spreading to the lymph nodes and finally the testicles. To date, vaccination using B19 or RB51 vaccine is be the most effective method in controlling and preventing brucellosis (Sousa et al., 2017; Asinamai et al., 2018). Nevertheless, Chung et al. (2016), reported that only 17\% of Malaysia buffaloes were vaccinated due to the difficulty of vaccine administration and unpopular usage of vaccines. In Malaysia, vaccination against brucellosis will only be given once during an outbreak. Seropositive animals will be subjected to mandatory culling while the other animals in the same herd will be vaccinated with RB51 vaccine (Asinamai et al., 2018). On the other hand, Johne's disease is another contagious, untreatable, and typically fatal intestinal infection in ruminants (Manning, 2001). In the current case report, the buffalo bull did not demonstrate any sign of diarrhoea or corrugation of the colon probably the disease was still in the early stage. Khan and Line (2005), stated that affected animals may have thickened, nonulcerated mucosa thrown into prominent corrugation at the ileum region during the subclinical stage. Lesions may extend proximally and distally to the jejunum and colon as the disease progresses. As a result, progressive weight loss from mild to severe and intermittent diarrhoea will be observed due to protein-losing enteropathy and impairment of water absorption (Jesse et al., 2016). Nonetheless, the single largest problem in Johne's disease control is the difficulty of detecting these carrier animals that are not showing signs of illness. This disease has a slow progression and many animals are non-clinical carriers of the disease. Ziehl-Neelsen reagent used in this case study can be used to stain mycobacteria but is unable to distinguish M. paratuberculosis from other mycobacteria present in the soil, water, and the intestinal tract (Fiorentino et al., 2012). Thus, faecal culture is considered the only definitive and critical technique to diagnose Johne's disease although this method is technically difficult and time consuming (OIE, 2011). Conferring to Fiorentino et al. (2012), pooling faecal samples can be an excellent tool to monitor flock or herd animals over time which can be applied to the farm in this case report. The disease can then be confirmed either by using serological or molecular tools such as ELISA and polymerase chain reaction (PCR) methods.

In summary, the lack of specific health control programs for buffaloes in Malaysia makes it difficult to control both brucellosis and Johne's disease in these animals. In this clinical case, the prognosis for the buffalo bull was grave due to the concurrent diseases, where the animal was culled adhering to the test-and-slaughter policy. A delay in detection will eventually lead to a catastrophic disease outbreak causing a significant economic impact on the farm and to the country.

\section{REFERENCES}

-Abd El-Salam MH, E1-Shibiny S (2011). Dairy Sci. Technol. 91: 663. https://doi.org/10.1007/s13594-011-0029-2

-Asinamai AB, Yusuf A, Jesse FFA, Azlan CA, Mazlina M, Peter ID, Idris UH, Abd WH, Mohd AML (2018). Management of an outbreak of brucellosis in a multispecies ruminant farm in Malaysia. Pertanika J. Trop. Agric. Sci. 41(4): 1911-1918.

- Chung ELT, Jesse FFA, Ibrahim HH, Marza AD, ZamriSaad M, Haron AW, Lila MAM, Norsidin MJ (2016). Clinicopathology, hematology and biochemistry responses in buffaloes towards Pasteurella multocida type B:2 immunogen lypopolysaccharide via oral and intravenous routes of infection. Microb. Pathog. 91: 141-154. https:// doi.org/10.1016/j.micpath.2015.12.003

-Fiorentino MA, Gioffre A, Cirone K, Morsella C, Alonso B, Delgado F, Paolicchi F (2012). First isolation of Mycobacterium avium subsp. paratuberculosis in a dairy goat in Argentina: pathology and molecular characterization. Small Rumin. Res. 108: 133-136. https://doi.org/10.1016/j. smallrumres.2012.06.010

- Jesse FFA, Bitrus AA, Abba Y, Sadiq MA, Chung ELT, Hambali IU, Lila MAM, Haron AW (2016). Clinical and gross pathological findings of Johne's disease in a calf: a case report. J. Adv. Vet. Anim. Res. 3(3): 292-296. https://doi. org/10.5455/javar.2016.c165

-Jesse FFA, Chung ELT, Muniandy KV, Tan AHAR, Maslamany D, Lila MAM, Norsidin MJ (2018). A Short Note: a study in determining the correlation between cortisol concentration in vaccinated and non-vaccinated clinically infected pneumonic goats. Mal. J. Anim. Sci. 21(2): 123-128.

-Kahn CM, Line S (2005). The Merck Veterinary Manual 9th Edition. Merial, USA.

-Manning EJB (2001). Mycobacterium avium subspecies paratuberculosis: A review of current knowledge. J. Zoo Wildl.Med.32(3): 293-304. https://doi.org/10.1638/10427260(2001)032[0293:MASPAR]2.0.CO;2

- Office Internacional des Epizooties, OIE. (2011). Paratuberculosis (Johnes's disease). Manual of Diagnostic Test and Vaccines for Terrestrial Animals.

- Sousa MGS, Salvarani FM, Bomjardim HA, Broti MF, Barbosa JD (2017). Brucellosis in water buffaloes. Pesqui. Vet. Bras. 37(3): 234-240. https://doi.org/10.1590/s0100$736 \times 2017000300006$ 